\title{
Targeted delivery of antibiotics to the infected pulmonary tissues using ROS-responsive nanoparticles
}

\author{
Yu Wang ${ }^{1}$, Qian Yuan ${ }^{1}$, Wei Feng ${ }^{1}$, Wendan Pu ${ }^{2}$ Jun Ding ${ }^{3}$, Hongjun Zhang ${ }^{4}$, Xiaoyu Li ${ }^{5}$, Bo Yang ${ }^{1}$, Qing Dai ${ }^{1}$, \\ Lin Cheng ${ }^{1}$, Jinyu Wang ${ }^{6}$, Fengjun Sun ${ }^{1 *}$ (D) and Dinglin Zhang ${ }^{2^{*}}$ (I)
}

\begin{abstract}
Background: Immunocompromised individuals and those with lung dysfunction readily acquire pulmonary bacterial infections, which may cause serious diseases and carry a heavy economic burden. Maintaining adequate antibiotic concentrations in the infected tissues is necessary to eradicate resident bacteria. To specifically deliver therapeutics to the infected pulmonary tissues and enable controlled release of payloads at the infection site, a ROS-responsive material, i.e. 4-(hydroxymethyl) phenylboronic acid pinacol ester-modified a-cyclodextrin (Oxi-aCD), was employed to encapsulate moxifloxacin (MXF), generating ROS-responsive MXF-containing nanoparticles (MXF/Oxi-aCD NPs).

Results: MXF/Oxi-aCD NPs were coated with DSPE-PEG and DSPE-PEG-folic acid, facilitating penetration of the sputum secreted by the infected lung and enabling the active targeting of macrophages in the inflammatory tissues. In vitro drug release experiments indicated that MXF release from Oxi-aCD NPs was accelerated in the presence of $0.5 \mathrm{mM} \mathrm{H}_{2} \mathrm{O}_{2}$. In vitro assay with Pseudomonas aeruginosa demonstrated that MXF/Oxi-aCD NPs exhibited higher antibacterial activity than MXF. In vitro cellular study also indicated that folic acid-modified MXF/Oxi-aCD NPs could be effectively internalized by bacteria-infected macrophages, thereby significantly eradicating resident bacteria in macrophages compared to non-targeted MXF/Oxi-aCD NPs. In a mouse model of pulmonary $P$. aeruginosa infection, folic acid-modified MXF/Oxi-aCD NPs showed better antibacterial efficacy than MXF and non-targeted MXF/Oxi-aCD NPs. Meanwhile, the survival time of mice was prolonged by treatment with targeting MXF/Oxi-aCD NPs.
\end{abstract}

Conclusions: Our work provides a strategy to overcome the mucus barrier, control drug release, and improve the targeting capability of NPs for the treatment of pulmonary bacterial infections.

Keywords: ROS-responsive, Multifunctional nanomedicine, Targeted delivery, Antibacterial nanotherapy, Pulmonary infection

\section{Background}

Immunocompromised individuals and those with lung dysfunction are susceptible to pulmonary bacterial infections, such as Haemophilus species, Staphylococcus aureus, and Pseudomonas aeruginosa [1]. After infection,

*Correspondence: fengj_sun@163.com; zh18108@163.com zh18108@tmmu.edu.cn

1 Department of Pharmacy, Southwest Hospital, Army Medical University (Third Military Medical University), Chongqing 400038, China

2 Department of Chemistry, College of Basic Medicine, Army Medical University (Third Military Medical University), Chongqing 400038, China

Full list of author information is available at the end of the article numerous macrophages are recruited to the infection sites, and activated macrophages play a key role in the defense against invasive bacteria, viruses and fungi $[2,3]$. Bacteria bound to the surface of macrophages are easily internalized into phagosomes and eventually digested [4]. However, some pathogens can escape host macrophagemediated destruction through a TNF receptor-dependent mechanism [5]. Therefore, treatment with antibiotics (e.g., moxifloxacin) is still an effective strategy to eradicate residual bacteria. Moxifloxacin (MXF), a broad-spectrum antibiotic, has enhanced activity against both gram-positive cocci (such as Staphylococcus aureus, Streptococcus 
pneumonia, Streptococcus pyogenes, and Enterococcus faecalis) and gram-negative pathogens (such as E. coli and $P$. aeruginosa) [6]. However, MXF is a hydrophilic drug that is easily cleared from the body within $24 \mathrm{~h}$. To retain a sufficient concentration of MXF at the infection site, daily administration of MXF is necessary, which may result in dose-dependent side effects (such as hepatotoxicity) [7]. To solve this problem, nanoparticles (NPs) have been employed to encapsulate MXF to minimize the dosing frequency [8]. Nevertheless, the targeting capacity and controlled release behavior of MXF-loaded NPs need to be further optimized. To improve the targeting capability of NPs and eliminate intracellular pathogens, folic acid (FA)-modified NPs have been employed for targeted delivery of antibiotics to macrophages due to their overexpression of the folate receptors (FRs) $[9,10]$. FRs are a family of glycoproteins $(35-40 \mathrm{kDa})$, that can be divided into three isoforms: FR- $\alpha$, FR- $\beta$ and FR- $\gamma$ [11]. FR- $\alpha$ is overexpressed on many types of cancer cells, including lung, breast, kidney, brain, endometrium, and colon cancers [11]. FR- $\alpha$ has also been detected in some normal tissues, such as kidney epithelial cells. Nevertheless, the kidney is protected from big size folate conjugates by their inability to be filtered through the glomerulus [12]. FR- $\beta$ is overexpressed on activated macrophages. For example, Xia et al. demonstrated that only approximately $2 \%$ of $\mathrm{F} 4 / 80^{+}$-resident peritoneal macrophages expressed FR- $\beta$ after injection with sterile PBS, but $35 \%$ of $\mathrm{F} 4 / 80^{+}$resident peritoneal macrophages expressed FR- $\beta$ after injection with live P. aeruginosa [13]. Both FR- $\alpha$ and FR- $\beta$ exhibit strong affinity to FA. Therefore, FA-conjugated NPs and drugs have been widely used for imaging and targeted therapy of various diseases with infiltration of activated macrophage, such as inflammation, infection and tumor [14].

In addition to macrophages, neutrophils are also accumulated in the infection site due to the inflammatory response, resulting in the overproduction of reactive oxygen species (ROS), including hydroxyl radicals (.OH), hydrogen peroxide $\left(\mathrm{H}_{2} \mathrm{O}_{2}\right)$, superoxide $\left(\mathrm{O}^{2-}\right)$, and singlet oxygen $\left({ }^{1} \mathrm{O}_{2}\right)[15,16]$. ROS can inhibit the growth of microorganisms through oxidative damage of intracellular DNA $[17,18]$. Unfortunately, ROS may induce multidrug resistance (MDR) by activating self-protective mechanisms in bacteria [19]. Furthermore, a high level of ROS can cause cytotoxicity by oxidation of DNA, lipids, proteins and other biomolecules, which is relevant to the pathogenesis of many diseases [20]. On the other hand, the rational utilization of ROS can realize "smart" release of payloads from carriers in pathological tissues with high ROS levels [21]. Thioether, selenium-containing polymers, poly(thioketal) and arylboronate can serve as ROS-responsive drug/gene nanocarriers because these materials can be oxidized or degraded under certain concentrations of $\mathrm{H}_{2} \mathrm{O}_{2}$ [22]. Among these materials, phenylboronic acid and polymers containing its esterification product exhibit excellent ROS-sensitivity under a biologically relevant range of $\mathrm{H}_{2} \mathrm{O}_{2}(0.5-1.0 \mathrm{mM})$ [23]. In our previous studies, we prepared phenylboronic ester-modified cyclodextrin and fabricated NPs, which can be rapidly decomposed even in the presence of $0.5 \mathrm{mM} \mathrm{H}_{2} \mathrm{O}_{2}$ $[24,25]$. This finding suggested that our prepared materials can be used as drug carriers to achieve controlled release of payloads in pathological tissues with pathologically abnormal ROS levels [26].

Herein a multifunctional nanotherapy was developed, to facilitate mucus penetration, efficiently deliver antibiotics to infected pulmonary tissues, and enable controlled release of payloads in the high-ROS microenvironment. To this end, 4-(hydroxymethyl) phenylboronic acid pinacol ester (HPAP)-modified cyclodextrin $(\mathrm{Oxi}-\alpha \mathrm{CD})$ was used as a carrier to encapsulate MXF to prepare coreshell NPs (MXF/Oxi- $\alpha$ CD NPs) via a nanoprecipitation/ self-assembly method (Fig. 1). The surface of MXF/Oxi$\alpha C D$ NPs was coated with DSPE-PEG-FA and DSPE-PEG to achieve macrophage targeting and mucus penetration. The ROS-responsive NPs could smartly release their cargos at a high level of $\mathrm{H}_{2} \mathrm{O}_{2}$. In vitro antibacterial activity of nanoformulations was assessed with $P$. aeruginosa. MXF-loaded NPs exhibited enhanced antibacterial efficacy compared with free MXF. In vivo efficacy of MXF nanotherapies was evaluated in a murine model of pulmonary $P$. aeruginosa infection. FA-modified MXF/Oxi$\alpha C D$ NPs can efficiently eradicate bacteria resident in pulmonary tissues and prolong the survival time of mice with pulmonary infection.

\section{Materials and methods \\ Reagents}

$\alpha$-Cyclodextrin $(\alpha-C D)$ was purchased from Tokyo Chemical Industry Co., Ltd. (Tokyo, Japan). 1-(3-Dimethylaminopropyl)-3-ethylcarbodiimide hydrochloride (EDC. $\mathrm{HCl}$ ), 4-(hydroxymethyl) phenylboronic acid pinacol ester (HPAP), 4-dimethylaminopyridine (DMAP), 1,1'-carbonyldiimidazole (CDI), poly(lacticco-glycolic acid) (PLGA) and Pluronic F127 (a polyethylene oxide-polypropylene oxide-polyethylene oxide triblock copolymer, or PEO-PPO-PEO) were supplied by Sigma-Aldrich Co. (Shanghai, China). Lecithin (refined) was obtained from Alfa Aesar (Shanghai, China). 1,2-Distearoyl-sn-glycero-3-phosphoethanolamine$N$-methoxy(polyethylene glycol)-2000 (DSPE-PEG ${ }_{2000}$ ) and folic acid-conjugated 1,2-distearoyl-sn-glycero3-phosphoethanolamine- $N$-methoxy(polyethylene glycol)-3400 (DSPE-PEG ${ }_{3400}$-FA) were provided by Xian Ruixi Corporation (Xian, China). Cy5 free acid and 


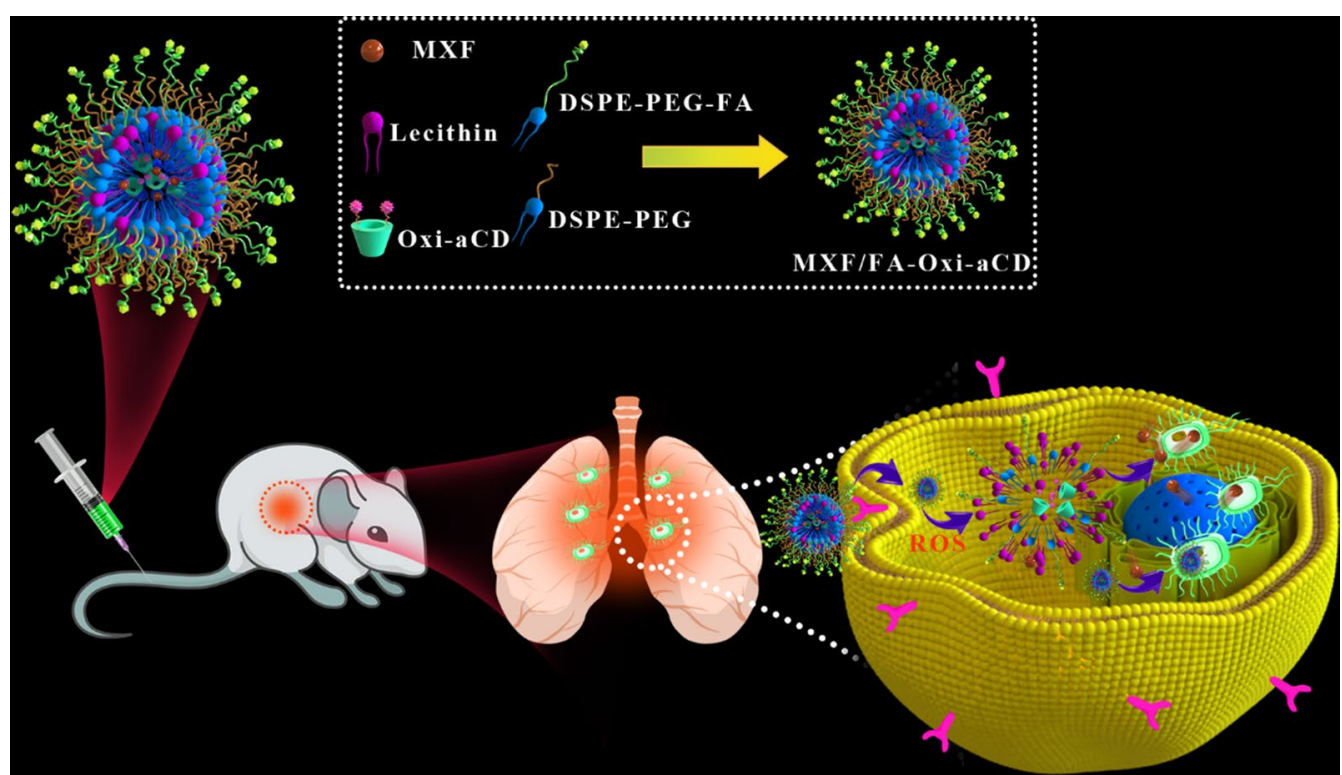

Fig. 1 Schematic illustration of fabrication of ROS responsive MXF/FA-Oxi-aCD NPs and their application for targeted treatment of pulmonary $P$. aeruginosa infection

Cy5-NHS ester were provided by Lumiprobe, LLC. (Hallandale Beach, FL, USA). LIVE/DEAD ${ }^{\circledR}$ BacLight $^{\text {TM }}$ Bacterial Viability Kit (L7012) and SYTO 9 Green Fluorescent Nucleic Acid Stain were purchased from Thermo Fisher Scientific Inc. (Waltham, MA, USA). Dulbecco's modified Eagle's medium (DMEM) and fetal bovine serum were obtained from HyClone Inc. (Waltham, MA, USA). Streptomycin-penicillin solution was purchased from Solarbio Life Sciences Co., Ltd. (Beijing, China). 4',6-Diamidino-2-phenylindole (DAPI) and a Hydrogen Peroxide Assay Kit (S0038) were provided by Beyotime Biotechnology Co., Ltd. (Shanghai, China).

\section{Cells and bacteria}

The human lung epithelial cell line A549 and the mouse monocyte macrophage cell line RAW264.7 were obtained from the Cell Bank of the Chinese Academy of Sciences (Shanghai, China). Cells were incubated in DMEM supplemented with $10 \%$ fetal bovine serum, $100 \mu \mathrm{g} / \mathrm{mL}$ streptomycin, and $100 \mathrm{IU}$ penicillin at $37{ }^{\circ} \mathrm{C}$ in a humidified atmosphere containing $5 \% \mathrm{CO}_{2}$.

The following isolates were obtained from patients with pulmonary infections at the First Affiliated Hospital of the Army Medical University (Third Military Medical University): P. aeruginosa P304, P386, P582, P671, P723, P727 and P729; K. pneumoniae K253, K288 and K302; E. coli E282, E325, E611 and E640; and S. aureus S23 and S49. All the bacteria were incubated on Columbia blood agar plates at $37^{\circ} \mathrm{C}$. Then a single colony on the plate was picked and incubated in LB medium overnight at $37{ }^{\circ} \mathrm{C}$.
Subsequently, the concentration of bacterial solution was adjusted to $1.0 \times 10^{6}$ colony forming units (CFU)/ $\mathrm{mL}$ (Mc. turbidity) to determine the minimum inhibitory concentration (MIC) of MXF nanoformulations. The P727 isolate is a multidrug resistant strain, and therefore it was chosen to evaluate in vitro and in vivo antibacterial efficacy of MXF-loaded NPs in the lung infection with $P$. aeruginosa. A total of $1.0 \times 10^{6}$ and $1.0 \times 10^{8} \mathrm{CFU} / \mathrm{mL}$ of the P727 isolate was employed to infect A549/RAW264.7 cells and mice, respectively.

\section{Animals}

Six-week-old female Kunming (KM) mice weighing $33 \mathrm{~g}$ were supplied from the experimental animal center of Army Medical University (Chongqing, China) and kept in an SPF-level sterile animal room. All animal experiments were performed in accordance with the guidelines approved by the ethics committee of Army Medical University (Chongqing, China).

\section{Synthesis of a ROS-responsive $a-C D$ material (Oxi-aCD)}

A ROS-responsive material was synthesized as previously reported [24]. In brief, HPAP $(2.00 \mathrm{~g}, 8.5 \mathrm{mmol})$ was reacted with CDI $(2.76 \mathrm{~g}, 17 \mathrm{mmol})$ in dry dichloromethane (DCM, $20 \mathrm{~mL}$ ) to obtain CDI-activated HPAP $(2.50 \mathrm{~g})$. With DMAP $(1.00 \mathrm{~g}, 8.1 \mathrm{mmol})$ as a catalyst, the Oxi- $\alpha C D$ material $(0.735 \mathrm{~g})$ was prepared by reacting CDI-activated HPAP $(2.0 \mathrm{~g}, 6.1 \mathrm{mmol})$ with $\alpha$-CD $(0.33 \mathrm{~g}, 0.338 \mathrm{mmol})$ in DMSO $(20 \mathrm{~mL})$. The structure of the resulting material was confirmed by ${ }^{1} \mathrm{H}$ NMR spectra. 


\section{Synthesis of Cy5-labeled Oxi-aCD}

Cy5 free acid (5.0 mg, $0.00963 \mathrm{mmol})$, DMAP (2.0 mg, $0.0164 \mathrm{mmol})$, and EDC. $\mathrm{HCl}(7.4 \mathrm{mg}, 0.0385 \mathrm{mmol})$ were dissolved in $5.0 \mathrm{~mL}$ of DMF, into which $50.0 \mathrm{mg}$ of $\alpha-C D(0.0514 \mathrm{mmol})$ was added and reacted at $25^{\circ} \mathrm{C}$ for 2 days. After removal of the organic solvent, the residue was washed with acetone to obtain Cy5-conjugated $\alpha-C D$. Using DMAP $(150.0 \mathrm{mg} 1.216 \mathrm{mmol})$ as a catalyst, Cy5-conjugated $\alpha$-CD $(50.0 \mathrm{mg})$ was reacted with CDIactivated HPAP (300.0 mg, $0.915 \mathrm{mmol}$ ) to obtain Cy5labeled Oxi- $\alpha C D$.

\section{Preparation and characterization of nanoparticles}

A modified nanoprecipitation/self-assembly method was employed to prepare MXF/Oxi- $\alpha C D$ NPs [25]. Briefly, $6.0 \mathrm{mg}$ of DSPE-PEG ${ }_{2000}$ and $4.0 \mathrm{mg}$ of lecithin were dispersed in $400 \mu \mathrm{L}$ of ethanol and $10.0 \mathrm{~mL}$ of deionized water, followed by preheating at $65^{\circ} \mathrm{C}$ for $30 \mathrm{~min}$. In parallel, $5.0 \mathrm{mg}$ MXF and $50.0 \mathrm{mg}$ Oxi- $\alpha \mathrm{CD}$ were dissolved in $2.0 \mathrm{~mL}$ of methanol, and the obtained solution was added dropwise into the above preheated dispersion with vortexing for $3 \mathrm{~min}$. After self-assembly for $2 \mathrm{~h}$ at $25^{\circ} \mathrm{C}$, MXF/Oxi- $\alpha$ CD NPs were harvested by centrifugation at $10,000 \mathrm{rpm}(7620 \mathrm{~g})$ for $10 \mathrm{~min}$, washed with 5\% F127 $(10.0 \mathrm{~mL})$ and resuspended in $0.2 \mathrm{~mL}$ of ultrapure water. Following similar procedures, Cy5-labeled Oxi- $\alpha$ CD NPs and blank Oxi- $\alpha C D$ NPs (without MXF) were prepared. In addition, FA-modified MXF/Oxi- $\alpha C D$ NPs (abbreviated as MXF/FA-Oxi- $\alpha$ CD NPs) were also fabricated with a similar method, in which $4.0 \mathrm{mg}$ of DSPE-PEG 2000 and $4.0 \mathrm{mg}$ of DSPE-PEG 3400 -FA were used. Cy5-labeled and blank PLGA NPs were prepared through an emulsion solvent evaporation method. Briefly, in a $50 \mathrm{~mL}$ centrifuge tube, $5.0 \mathrm{mg}$ of MXF or $1 \mathrm{mg}$ of Cy5 dye, and $50.0 \mathrm{mg}$ of PLGA, were dissolved in $0.7 \mathrm{~mL}$ of dichloromethane, then $7.0 \mathrm{~mL}$ of $1 \%$ PVA was added, followed by sonication for $2 \mathrm{~min}$ in an ice bath with a probe sonicator. The obtained emulsion was poured into $20.0 \mathrm{~mL}$ of $0.3 \%$ PVA and stirred for $2 \mathrm{~h}$ at $25^{\circ} \mathrm{C}$. PLGA NPs were harvested by centrifugation at $10,000 \mathrm{rpm}(7620 \mathrm{~g})$ for $10 \mathrm{~min}$, washed three times with $10.0 \mathrm{~mL}$ of 5\% F127 and resuspended in $0.2 \mathrm{~mL}$ of ultrapure water.

The size distribution and zeta-potential of NPs were measured by dynamic light scattering (DLS) analysis and laser Doppler electrophoresis, respectively (Malvern Zetasizer Nano ZS, Malvern, U.K.). The morphology of NPs was characterized by transmission electron microscopy (TEM) (JEM-1400, Japan).

\section{Drug loading and in vitro drug release study}

To quantify the MXF content in NPs, $20 \mu \mathrm{L}$ of fresh NPs suspension was lyophilized, weighed, and dissolved in
$1.0 \mathrm{~mL}$ of methanol. The MXF concentration was measured by HPLC. Drug loading (DL) was calculated according to the following equation:

DL $\%=($ Amount of MXF in NPs/Weight of NPs $) \times 100 \%$.

To study the drug release behavior of NPs in vitro, $200 \mu \mathrm{L}$ of suspensions containing newly prepared MXF/ Oxi- $\alpha C D$ NPs or MXF/FA-Oxi- $\alpha C D$ NPs was separately added into dialysis tubing (MWCO: $3500 \mathrm{Da}$ ), which was immersed into $40.0 \mathrm{~mL}$ of PBS with or without $0.5 \mathrm{mM}$ $\mathrm{H}_{2} \mathrm{O}_{2}$ at $37{ }^{\circ} \mathrm{C}$. At predetermined time points, $4.0 \mathrm{~mL}$ of supernatant was withdrawn from the external medium and replaced with fresh medium. The concentration of MXF at each time point was determined by HPLC.

\section{Cytotoxicity evaluation by CCK-8 assay}

RAW264.7 and A549 cells were seeded in DMEM at $1 \times 10^{4}$ cells/well in 96-well plates for $24 \mathrm{~h}$ before treatment. Cells were coincubated with MXF and different NPs formulations at various concentrations for $24 \mathrm{~h}$. Then $10 \mu \mathrm{L}$ of CCK-8 solution was added into each well and cultured for another $1 \mathrm{~h}$. The absorbance of cultures was detected at $450 \mathrm{~nm}$ using a Thermo Multiskan Spectrum spectrophotometer (Thermo Fisher Scientific Inc. MA, USA).

\section{Cell uptake}

RAW264.7 and A549 cells were seeded at $1 \times 10^{5}$ cells/ well in 24-well plates and allowed to grow for $24 \mathrm{~h}$. Then the cells were infected with the P727 isolate stained with SYTO 9 (at a ratio of $1: 10$ ) at $37{ }^{\circ} \mathrm{C}$ for $4 \mathrm{~h}$. After infection, the cells were treated with free $\mathrm{Cy} 5$, Cy5/Oxi$\alpha C D$ NPs, or Cy5/FA-Oxi- $\alpha$ CD NPs for 1 or 4 h. Cells treated with fresh culture medium served as a control. The treated cells were washed three times with $1.0 \mathrm{~mL}$ of PBS, fixed in 4\% paraformaldehyde for $15 \mathrm{~min}$, and rinsed three times with $1.0 \mathrm{~mL}$ of PBS. Cell nuclei were stained with DAPI for $10 \mathrm{~min}$. After three times of washing with $1.0 \mathrm{~mL}$ of PBS, the cell uptake efficiency was detected by confocal laser scanning microscopy (CLSM) (Blue fluorescence, excitation at $405 \mathrm{~nm}$ and emission at $453 \mathrm{~nm}$; Green fluorescence, excitation at $488 \mathrm{~nm}$ and emission at $561 \mathrm{~nm}$; Red fluorescence, excitation at $633 \mathrm{~nm}$ and emission at $699 \mathrm{~nm}$ ).

We also investigated the uptake behavior of RAW264.7 cells by flow cytometry. As described above, the infected cells were treated with cell culture medium (control group), Cy5, Cy5/Oxi- $\alpha \mathrm{CD}$ NPs, or Cy5/FA-Oxi- $\alpha \mathrm{CD}$ NPs for $1 \mathrm{~h}$ and then washed three times with $1.0 \mathrm{~mL}$ of PBS. The cells were harvested and detected by flow cytometry (Accuri C6, Becton, Dickinson and Company, USA). 


\section{Determination of the minimum inhibitory concentration (MIC)}

The MIC of MXF, blank NPs, MXF/Oxi- $\alpha$ CD NPs, and MXF/FA-Oxi- $\alpha$ CD NPs was separately determined using the agar dilution method [27]. Briefly, different concentrations of MXF in PBS were obtained from the stock solutions (initial concentration, $240 \mu \mathrm{g} / \mathrm{mL}$ ) by serial dilution. Then, $1.0 \mathrm{~mL}$ of drug solution and $14.0 \mathrm{~mL}$ of Mueller-Hinton agar (MHA) were added into the cell culture dish and fully mixed. After solidification, all the bacterial suspensions $\left(1 \times 10^{6} \mathrm{CFU} / \mathrm{mL}\right)$ were inoculated with the antibacterial determiners. After incubation at $37{ }^{\circ} \mathrm{C}$ for $24 \mathrm{~h}$, the inhibitory effects of these drugs were determined and calculated.

\section{Biofilm formation assays}

P727 isolate cultures were adjusted to $1 \times 10^{6} \mathrm{CFU} / \mathrm{mL}$ and inoculated in 96-well plates with LB broth in the presence of $1 / 4 \times \mathrm{MIC}$ of MXF or nanoformulations. After incubation at $37^{\circ} \mathrm{C}$ for $24 \mathrm{~h}$, the plates were rinsed three times with $1.0 \mathrm{~mL}$ of PBS and dried at $25^{\circ} \mathrm{C}$. Subsequently, the adherent cells were stained with $1 \%$ crystal violet (Sigma-Aldrich, USA) for $10 \mathrm{~min}$ and then rinsed three times with $1.0 \mathrm{~mL}$ of sterile water. After the plates were dried, the dye was dissolved in 30\% acetic acid, and the absorbance of the solubilized dye was detected at $590 \mathrm{~nm}$ using a Thermo Multiskan Spectrum spectrophotometer (Thermo Fisher Scientific Inc. MA, USA). Each treatment was assayed in three wells per plate, and the experiments were repeated three times.

\section{Intracellular antibacterial activity assays}

The antibacterial effects of MXF, blank NPs, MXF/Oxi$\alpha C D$ NPs, and MXF/FA-Oxi- $\alpha$ CD NPs on intracellular infection were also tested. RAW264.7 cells were plated in 12-well plates with $2 \times 10^{5}$ cells per well. In parallel, precultured bacteria were diluted with DMEM to $1 \times 10^{6} \mathrm{CFU} / \mathrm{mL}$. RAW264.7 cells were infected with diluted bacteria (at a ratio of $1: 10$ ) at $37^{\circ} \mathrm{C}$ for $4 \mathrm{~h}$. Cells treated with fresh culture medium were used as the control. Then, the supernatant was removed, and the residual cells were washed with $1.0 \mathrm{~mL}$ of gentamicin-containing PBS solution $(100 \mu \mathrm{g} / \mathrm{mL})$ three times to kill extracellular bacteria. The washed cells were then incubated with $1 / 4 \times$ MIC of MXF, blank NPs, MXF/Oxi- $\alpha$ CD NPs or MXF/FA-Oxi- $\alpha$ CD NPs at $37{ }^{\circ} \mathrm{C}$ for 4 or $24 \mathrm{~h}$. Subsequently, cells were harvested and lysed with Triton X-100 for $15 \mathrm{~min}$. The cell suspensions were diluted 10 -fold or 100 -fold with saline and plated on agar plates at $37^{\circ} \mathrm{C}$ for $24 \mathrm{~h}$. The number of colonies was counted to assess the antibacterial effect of different formulations.
Confocal laser scanning microscopy (CLSM)

Viability of the P727 isolate was tested using a LIVE/ DEAD $^{\circledR}$ BacLight $^{\mathrm{TM}}$ Bacterial Viability Kit (L7012) after treatment with various formulations. Briefly, the P727 isolates $\left(1 \times 10^{6} \mathrm{CFU} / \mathrm{mL}\right)$ were incubated with culture medium (control group), MXF, blank NPs, MXF/Oxi$\alpha C D$ NPs, or MXF/FA-Oxi- $\alpha$ CD NPs at $1 / 4 \times$ MIC of MXF for $4 \mathrm{~h}$. Then a dye mixture (SYTO 9 dye and propidium iodide (PI) at a ratio of $1: 1)$ was added to the bacterial suspension (at a ratio of $3 \mu \mathrm{L}: 1.0 \mathrm{~mL}$ ). The bacterial suspensions were incubated for another $15 \mathrm{~min}$ in the dark at $25{ }^{\circ} \mathrm{C}$ and then observed using CLSM (Green fluorescence, excitation at $488 \mathrm{~nm}$ and emission at $522 \mathrm{~nm}$; Red fluorescence, excitation at $561 \mathrm{~nm}$ and emission at $632 \mathrm{~nm})$.

The interaction of Oxi- $\alpha C D$ NPs and bacteria was also recorded using CLSM. Briefly, the P727 isolate $\left(1 \times 10^{6}\right.$ $\mathrm{CFU} / \mathrm{mL}$ ) was incubated with Cy5-labeled Oxi- $\alpha$ CD NPs for $2 \mathrm{~h}$. The microscopic images were acquired by CLSM.

\section{Transmission electron microscopy (TEM)}

The morphology of the P727 isolate after treatment with various formulations was observed by TEM (JEM-1400, Japan). After overnight culture, the bacterial suspension was diluted in saline to a concentration of $1 \times 10^{6} \mathrm{CFU} /$ $\mathrm{mL}$. Then, bacteria were treated with $1 / 4 \times \mathrm{MIC}$ of MXF, blank NPs, MXF/Oxi- $\alpha$ CD NPs or MXF/FA-Oxi- $\alpha C D$ NPs for $4 \mathrm{~h}$. An untreated bacterial suspension was used as the control. After removing the supernatant, the collected bacterial cells were fixed with $2.5 \%$ glutaraldehyde overnight, and the morphology of the bacterial cells was observed by TEM.

\section{Mucus penetration assay}

The mucus penetration capability of Cy5-labeled Oxi$\alpha C D$ NPs was determined using sputum from a patient with lung infection. Cy5-labeled PLGA NPs without PEG modification were used as the negative control. Cy5/Oxi$\alpha C D$ NPs and Cy5/PLGA NPs were separately added to the sputum, and the distribution of these NPs was observed by CLSM at 0 and $3 \mathrm{~h}$.

\section{Determination of intracellular and extracellular $\mathrm{H}_{2} \mathrm{O}_{2}$ generation in RAW 264.7 cells}

To determine the intracellular and extracellular $\mathrm{H}_{2} \mathrm{O}_{2}$ concentrations, RAW 264.7 cells $\left(2 \times 10^{5}\right.$ cells/well $)$ were seeded in 12-well plates and cultured for $24 \mathrm{~h}$. Then, the cells were infected with the P727 isolate for $4 \mathrm{~h}$ as previously described. After being washed with $1.0 \mathrm{~mL}$ PBS three times, the cells were incubated with various nanoformulations at $1 / 4 \times$ MIC of MXF for $24 \mathrm{~h}$. Cells without treatment were used as the control. The intracellular and extracellular concentrations of $\mathrm{H}_{2} \mathrm{O}_{2}$ were measured 
using a Hydrogen Peroxide Assay Kit according to the manufacturer's protocol.

\section{Establishment of a murine model of pulmonary infection}

A mouse model of pulmonary infection with the $P$. aeruginosa P727 isolate was established by a non-invasive tracheal intubation method. First, mice were administered an intraperitoneal injection of cyclophosphamide (Meilun, Liaoning Province, China) at $200 \mathrm{mg} / \mathrm{kg}$ body weight to induce immunosuppression 4 days prior to infection. Next, the immunosuppressed mice were anesthetized by an intraperitoneal injection of $1 \%$ pentobarbital $(40 \mathrm{mg}$ / $\mathrm{kg}$, Sigma, USA). Then, $50 \mu \mathrm{L}$ of P727 isolate solution $\left(1 \times 10^{8} \mathrm{CFU} / \mathrm{mL}\right)$ was injected into the lungs of the mice by orotracheal intubation under a transilluminating lamp. In contrast, the control group was treated with 50 $\mu \mathrm{L}$ of saline.

\section{In vivo biodistribution study}

The bacteria-infected mice were randomly assigned to three groups that were treated with Cy5 solution, Cy5labeled Oxi- $\alpha$ CD NPs, or Cy5-labeled FA-Oxi- $\alpha$ CD NPs via intravenous administration. The dose in each group was equivalent to $20 \mu \mathrm{g}$ of Cy5 per mouse. At 2, 4, 6, 8, 12 , and $24 \mathrm{~h}$ post injection, the mice were sacrificed. The main organs, including the heart, liver, spleen, lungs, and kidneys, were collected and rinsed with physiological saline. Then the Cy5 fluorescence intensity in organs was detected by a live animal imaging system (IVIS Spectrum, Perkin Elmer, USA) with a $640 \mathrm{~nm}$ excitation filter and a $700 \mathrm{~nm}$ emission filter.

\section{In vivo anti-infective activity}

The pulmonary infection model in immunosuppressed mice was established as described above. After inoculation for $24 \mathrm{~h}$, the infected mice were intravenously injected with saline, MXF, blank NPs, MXF/Oxi- $\alpha C D$ NPs, or MXF/FA-Oxi- $\alpha C D$ NPs at a dose of $5 \mathrm{mg} / \mathrm{kg}$ MXF once every 2 days post infection for a total of 2 treatments. Meanwhile, the control mice were treated with saline. The survival rate was determined by using the Kaplan-Meier method. After 6 days of treatment, the mice were sacrificed. The left lungs from the infected mice were harvested and fixed with $4 \%$ paraformaldehyde for $H \& E$ staining. If mice died during the experiments, the lung tissues was also collected for pathological analysis. The morphology of these organs was observed using an optical microscope (20×, Olympus, Japan). In addition, the right lung was weighed and homogenized under sterile conditions to determine $P$. aeruginosa bacteria counts. The homogenates were suspended in $1.0 \mathrm{~mL}$ of sterile saline, diluted quantitatively by serial dilution and then incubated on agar plates at $37{ }^{\circ} \mathrm{C}$ for $24 \mathrm{~h}$.
The number of colonies was counted $24 \mathrm{~h}$ later, and the results are presented as CFU/g lung weight.

\section{Statistical analysis}

All data are presented as the mean \pm standard deviation (SD) of at least three independent experiments. Statistical analysis was performed using one-way variance (ANOVA) for more than three groups and Student's $t$ test for two groups. Statistical significance was defined as ${ }^{*} P<0.05$ and ${ }^{* *} P<0.01$.

\section{Results and discussion}

\section{Synthesis and characterization of Oxi-aCD and Cy5-labeled} Oxi-aCD

Our previous work reported that 4-(hydroxymethyl) phenylboronic acid pinacol ester (HPAP)-modified cyclodextrin possesses excellent biocompatibility and ROS responsiveness and could serve as a superior drug delivery vehicle [24-26, 28]. Herein, our previously reported Oxi- $\alpha C D$ material was employed to encapsulate MXF. The synthesis method of Oxi- $\alpha C D$ is illustrated in Additional file 1: Scheme $\mathrm{S} 1$ and its ${ }^{1} \mathrm{H}$ NMR spectrum is shown in Additional file 1: Figure S1. To label the material with a fluorescent probe, Cy5 was conjugated onto $\alpha-C D$ with EDC.HCl and DMAP using as catalysts (Additional file 1: Scheme S2). As shown by the ${ }^{1} \mathrm{H}$ NMR spectrum in Additional file 1: Figure S2, in addition to the proton signals of Oxi- $\alpha C D$, the characteristic peaks of the methyl, double bond, and phenyl groups in Cy5 were clearly observed, indicating successful synthesis of Cy5labeled Oxi- $\alpha C D$.

\section{Fabrication and characterization of MXF/Oxi-aCD NPs}

$\mathrm{MXF} / \mathrm{Oxi}-\alpha \mathrm{CD}$ NPs were fabricated via a nanoprecipitation self-assembly method (Fig. 1). The physicochemical characterization of NPs is summarized in Table 1. DLS measurements showed that blank NPs, MXF/Oxi- $\alpha C D$ NPs, and MXF/FA-Oxi- $\alpha$ CD NPs had a mean diameter of $203.8 \pm 6.0,266.2 \pm 1.0$, and $254.2 \pm 9.5 \mathrm{~nm}$, with a polydispersity index (PDI) of $0.184 \pm 0.026,0.162 \pm 0.017$ and $0.213 \pm 0.008$, respectively. All the NPs exhibited negative or low zeta-potential (from -32.4 to $-37.4 \mathrm{mV}$ ) in $0.01 \mathrm{M} \mathrm{PBS}$ at $\mathrm{pH}$ 7.4. It is worth noting that Cy5labeling did not significantly alter the size distribution, PDI, and zeta-potential of Oxi- $\alpha C D$ NPs. The morphology of MXF/Oxi- $\alpha C D$ NPs and MXF/FA-Oxi- $\alpha C D$ NPs was characterized by TEM. The TEM images confirmed that all the NPs were spherical and homogenous (Fig. 2a, d). DLS measurements also confirmed that these NPs were mainly distributed from 200 to $300 \mathrm{~nm}$ (Fig. 2b, e). HPLC quantification revealed that the MXF drug loading efficiency of Oxi- $\alpha$ CD NPs and FA-Oxi- $\alpha C D$ NPs was $5.78 \pm 0.51 \%$ and $7.89 \pm 0.45 \%$, respectively (Table 1 ). The 
Table 1 The physicochemical characterization of NPs

\begin{tabular}{lllll}
\hline Nanoformulations & Particle size $(\mathbf{n m})$ & Zeta-potential $(\mathbf{m V})$ & PDI & Drug loading (\%) \\
\hline Blank NPs & $203.8 \pm 6.0$ & $-37.4 \pm 0.7$ & $0.184 \pm 0.026$ & - \\
MXF/Oxi-aCD NPs & $266.2 \pm 1.0$ & $-22.4 \pm 0.8$ & $0.162 \pm 0.017$ & $5.78 \pm 0.51$ \\
MXF/FA-Oxi-aCD NPs & $254.2 \pm 9.5$ & $-32.4 \pm 0.4$ & $0.213 \pm 0.008$ & $7.89 \pm 0.45$
\end{tabular}

Data represent mean $\pm S D(n=3)$

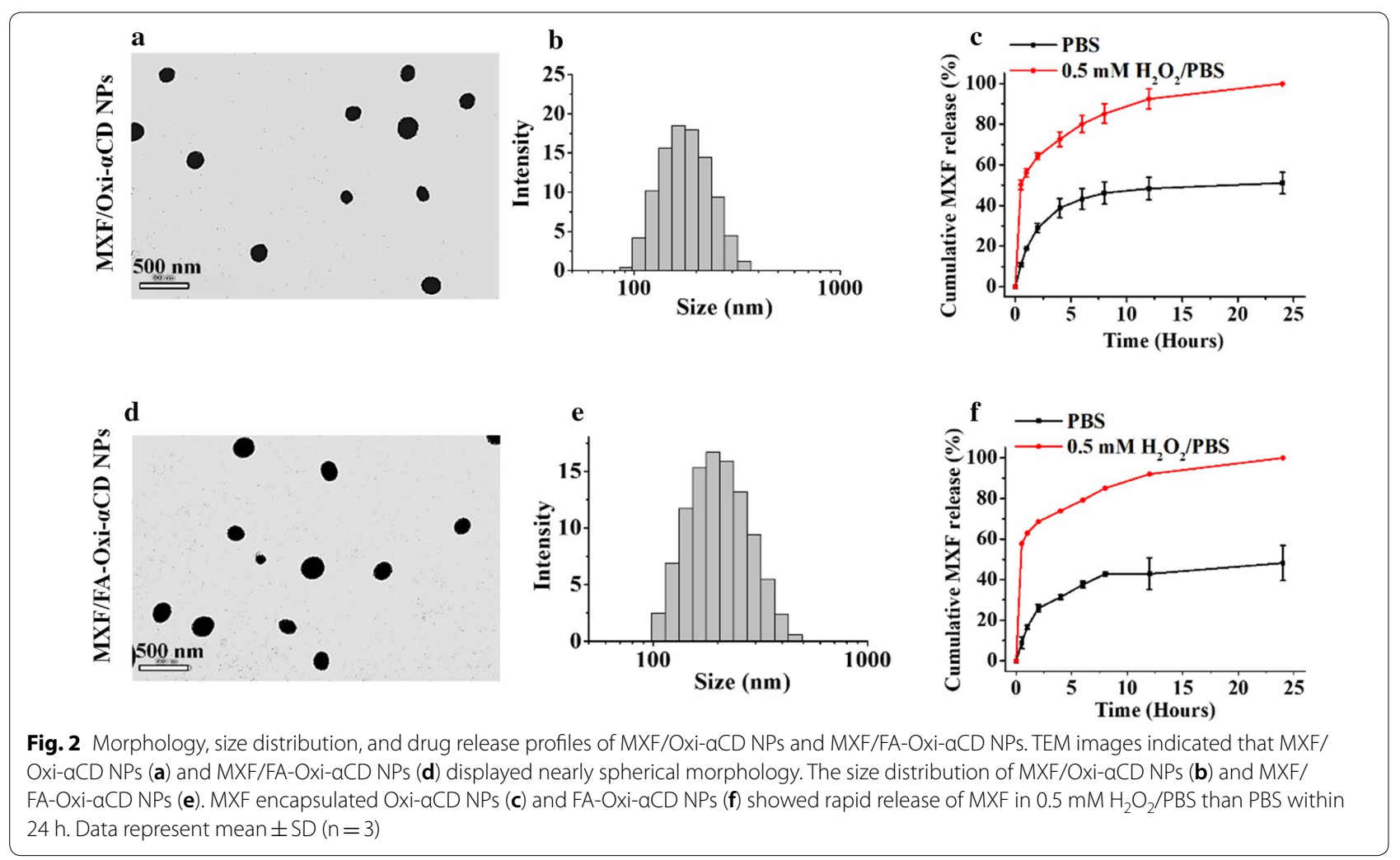

drug release behaviors of MXF/Oxi- $\alpha \mathrm{CD}$ NPs and MXF/ FA-Oxi- $\alpha C D$ NPs were also investigated. The release of MXF from MXF/Oxi- $\alpha C D$ NPs and MXF/FA-Oxi- $\alpha C D$ NPs was accelerated in $0.5 \mathrm{mM} \mathrm{H}_{2} \mathrm{O}_{2}$ (Fig. 2c, f), suggesting that controlled release of MXF from Oxi- $\alpha C D$ NPs occurred in the pathological tissues with high levels of $\mathrm{H}_{2} \mathrm{O}_{2}$. However, approximately 50\% MXF was released from Oxi- $\alpha C D$ NPs in PBS within 24 h (Fig. 2c, f), perhaps because the hydrophilicity of MXF facilitated leakage from the NPs. Interestingly, a similar drug release rates were found for the FA-bearing and the non-targeted nanoformulations. In this study, the amount of FA in the total lipid was approximately 3\% (weight ratio). Therefore, the introduction of FA did not significantly alter the physicochemical properties of the NPs, such as particles size, PDI, and drug loading (Table 1). FA-modification also did not change the hydrophobic properties of NPs. Therefore, FA-modified NPs had similar drug release behaviors as the non-targeted NPs.

Macrophages infected with bacteria showed increased ROS generation [29]. To verify whether Oxi- $\alpha C D$ NPs can consume intracellular and extracellular hydrogen peroxide, the P727 isolate-infected RAW 264.7 cells were treated with blank PLGA NPs (non-ROS-responsive), blank Oxi- $\alpha C D$ NPs, MXF/Oxi- $\alpha C D$ NPs and MXF/ FA-Oxi- $\alpha C D$ NPs. Compared to the control and blank PLGA NPs groups, the intracellular hydrogen peroxide concentration was decreased after infected cells were treated with ROS-responsive NPs (Additional file 1: Figure S3A), indicating these NPs can eliminate hydrogen peroxide. Also, the extracellular hydrogen peroxide concentration decreased significantly when infected cells 
were treated with ROS-responsive NPs compared to their counterparts (Additional file 1: Figure S3B). This may be attributed to the fact that the extracellular hydrogen peroxide concentration is far lower than the corresponding intracellular concentration, and this difference is obviously affected by carrier exhaustion. Furthermore, the cytotoxicity of MXF and the nanoformulations on RAW264.7 and A549 cells was evaluated. The viability of RAW264.7 and A549 cells incubated with MXF and nanoformulations showed no significant differences, indicating that Oxi- $\alpha \mathrm{CD}$ NPs had no obvious cytotoxicity (Additional file 1: Figure S4).

\section{Cellular uptake}

Targeting delivery of antibiotics to macrophages is an effective strategy to eradicate cellular bacteria $[9,10]$. It has been reported that FR is overexpressed on the surface of activated macrophages (i.e., bacteria and virusinfected macrophages) [9]. Modification of NPs with FA can enhance their targeting capacity to FR-overexpressing macrophages [11]. To target bacteria-infected macrophages, DSPE-PEG-FA was employed to coat Oxi- $\alpha C D$ NPs. To investigate whether FA-coating can enhance the cellular uptake of Oxi- $\alpha C D$ NPs by macrophages, the cellular uptake of free Cy5-NHS ester and Cy5-labeled Oxi- $\alpha C D$ NPs by bacteria-infected RAW264.7 (high FR expression) and A549 cells (low FR expression) was evaluated using CLSM. As shown in Additional file 1: Figure S5, after $1 \mathrm{~h}$ of incubation, compared with free Cy5, Cy5-labeled Oxi- $\alpha$ CD NPs and FA-Oxi- $\alpha C D$ NPs showed stronger red fluorescence signals inside RAW264.7 cells. This suggested that NPs could be efficiently internalized by macrophages. With prolonged incubation time to $4 \mathrm{~h}$, the red fluorescence signals inside RAW264.7 cells were significantly increased, indicating that the uptake of NPs is time-dependent (Fig. 3). Remarkably, Cy5labeled FA-Oxi- $\alpha C D$ NPs exhibited stronger fluorescence signals than non-targeted NPs at different time points (Additional file 1: Figure S5 and Fig. 3), implying that the internalization of FA-modified NPs was mediated by FR on the macrophage surface. Furthermore, the uptake of Cy5-labeled Oxi- $\alpha$ CD NPs and FA-Oxi- $\alpha$ CD NPs by A549 cells was also investigated (Additional file 1: Figure S6). A549 cells treated with Cy5/Oxi- $\alpha$ CD NPs and Cy5/ FA-Oxi- $\alpha C D$ NPs had almost the same red fluorescence signals due to low FR expression on the surface.

Meanwhile, we quantified cell uptake efficiency using flow cytometry. Compared with Cy5, Cy5-labeled Oxi$\alpha C D$ NPs and FA-Oxi- $\alpha C D$ NPs had higher uptake efficiencies (Additional file 1: Figure S7). Cy5-labeled FA-Oxi- $\alpha C D$ NPs achieved the highest uptake efficiency, indicating a consistent trend with the CLSM results. The abovementioned results suggested that FA-modified
Oxi- $\alpha C D$ NPs could be efficiently internalized by bacteria-infected macrophages. Consequently, FA-modified Oxi- $\alpha C D$ NPs can serve as an effective drug delivery vehicles for targeted delivery of antibiotics to infected pulmonary tissues.

\section{In vitro antibacterial activities of the NPs}

As described above, Oxi- $\alpha C D$ NPs can serve as an effective vehicles to deliver antibiotics to bacteria-infected macrophages. Therefore, we further investigated in vitro antibacterial activities of MXF-loaded Oxi- $\alpha C D$ NPs. The MIC value is an important parameter for evaluating the antimicrobial activity of drugs. Gram-negative and grampositive bacteria isolated from patients with pulmonary infection were selected to test the MIC values of MXF and its nanoformulations. For all tested bacteria, the MIC of blank NPs was greater than $16 \mu \mathrm{g} / \mathrm{mL}$ (Table 2), implying that blank NPs have no antibacterial activity against the tested bacteria. However, MXF could significantly inhibit the growth of K288, E325, S23, P304, P723, and P729 bacteria, and the MIC of MXF for the above bacteria was less than $4 \mu \mathrm{g} / \mathrm{mL}$. Compared with MXF, the MXF/Oxi- $\alpha C D$ NPs and MXF/FA-Oxi- $\alpha C D$ NPs had obviously decreased MIC values in MXF-sensitive bacteria. For example, the MIC of MXF for the S23 isolate was $0.25 \mu \mathrm{g} / \mathrm{mL}$. The MIC of MXF/Oxi- $\alpha$ CD NPs and MXF/ FA-Oxi- $\alpha C D$ NPs was decreased to $0.031 \mu \mathrm{g} / \mathrm{mL}$. For the P723 isolate, the MIC of MXF/Oxi- $\alpha$ CD NPs and MXF/ FA-Oxi- $\alpha C D$ NPs was $1 \mu \mathrm{g} / \mathrm{mL}$, which is only one-quarter that of MXF. The results verified that MXF-loaded NPs had better antibacterial activity than free MXF. Similar MICs were observed for MXF/Oxi- $\alpha$ CD NPs and MXF/FA-Oxi- $\alpha C D$ NPs in the previously mentioned bacteria, indicating that FA modification did not alter the antibacterial activity of nanomedicines. Among these bacterial strains, $P$. aeruginosa is one of the most common pathogens related to bacterial infection in the lung. Due to the MDR of $P$. aeruginosa, the infected bacteria is difficult to completely eradicate from infection tissues [30]. According to our results (Table 2), P304, P386, P723, and P729 strains are sensitive to MXF. Therefore no significant difference in the antibacterial efficacy was found for MXF and MXF-loaded NPs. On the other hand, both MXF and MXF-loaded ROS-responsive NPs exhibited poor antibacterial effects on the P582 strain. Both the P671 and P727 strains showed resistant to MXF, but the P671 strain was sensitive to ciprofloxacin and levofloxacin, according to the results of the drug sensitivity tests in our hospital. In this study, we aimed to enhance the antibacterial efficacy of antibiotics and investigate the antibacterial mechanism of nanomedicines. Consequently, the P727 strain was selected as a model strain to further evaluate the antibacterial activity of MXF-loaded NPs. 


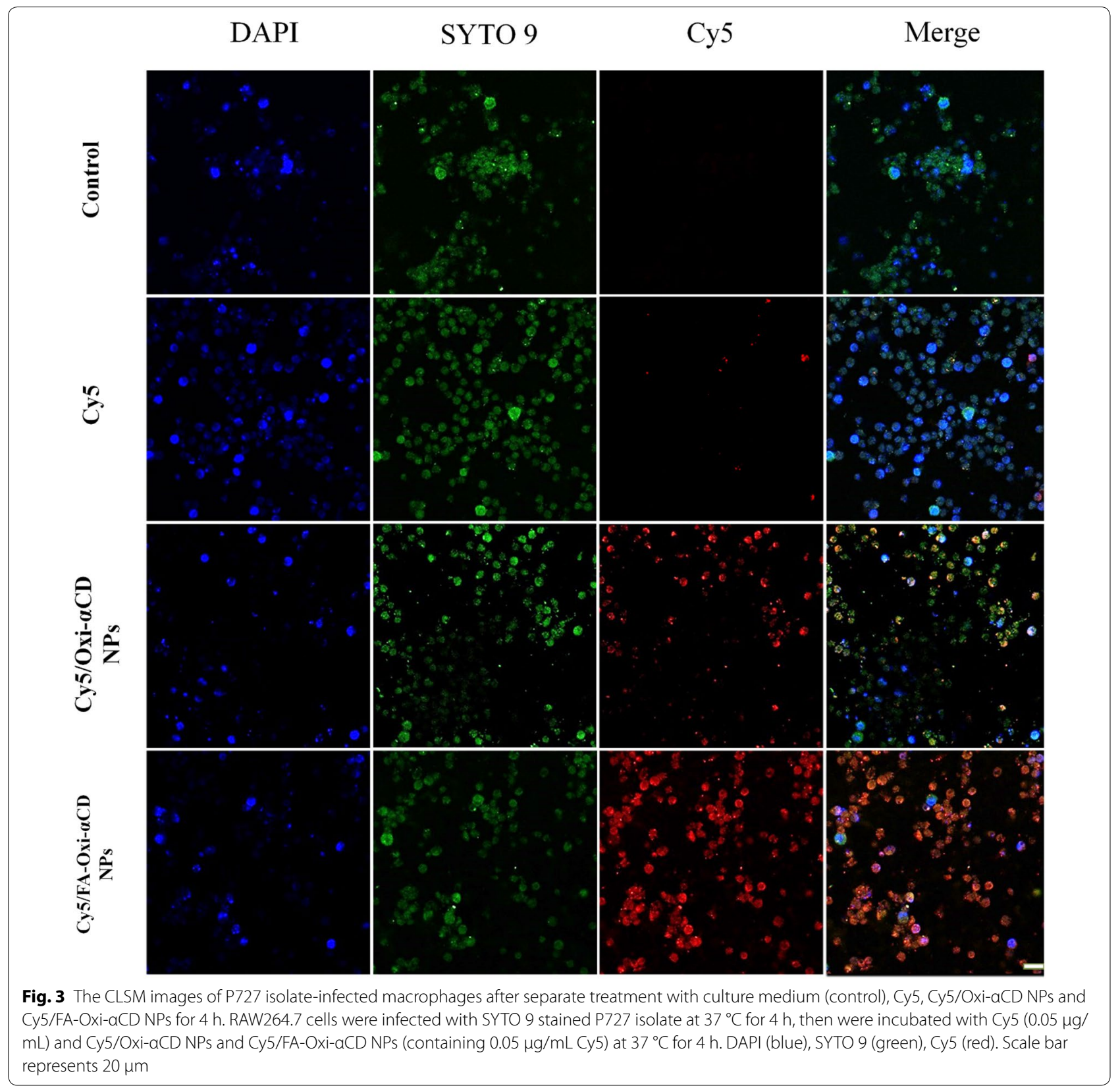

To further investigate the antibacterial activity of MXF and its nanoformulations, bacteria exposed to NPs were assayed using a LIVE/DEAD Bacterial Viability Kit and CLSM. To distinguish dead and live cells of the P727 isolate, live cells were stained with SYTO 9 (green), and dead cells were stained with PI (red). The stained P727 bacteria were observed by CLSM. As can be observed in Fig. 4, P727 bacteria treated with PBS or blank NPs showed a strong green fluorescence signal and weak red fluorescence, suggesting that blank NPs had no antibacterial effect. Compared to the control group, the MXF-treated group showed stronger red fluorescence and weaker green fluorescence, indicating that MXF can lead to P727 bacterial death. Interestingly, bacteria treated with MXF/Oxi- $\alpha$ CD NPs and MXF/FA-Oxi- $\alpha C D$ exhibited weaker green fluorescence signals than those treated with MXF, proving that these nanomedicines had stronger antibacterial activity than free drugs. Hong et al. investigated the antibacterial mechanism of NPs and proved that NPs could permeate the cell membrane of bacteria, thereby increasing their antibacterial efficiency [31]. MXF is a DNA topoisomerase inhibitor that inhibit bacterial growth by damaging cellular DNA [6]. The low MIC and high in vitro antibacterial activity suggested 
Table 2 The MIC values of antimicrobial agents against clinically isolated bacteria

\begin{tabular}{lllll}
\hline Strains & \multicolumn{2}{l}{ MIC $(\boldsymbol{\mu g} / \mathbf{m L})$} & \\
\cline { 2 - 5 } & Blank-NPs & MXF & MXF/Oxi-aCD NPs & $\begin{array}{l}\text { MXF/ } \\
\text { FA-Oxi- } \\
\text { aCD NPs }\end{array}$ \\
\hline K253 & $>16$ & 16 & 8 & 8 \\
K288 & $>16$ & 4 & 2 & 2 \\
K302 & $>16$ & $>16$ & $>16$ & $>16$ \\
E282 & $>16$ & $>16$ & $>16$ & $>16$ \\
E325 & $>16$ & 2 & 0.5 & 0.5 \\
E611 & $>16$ & $>16$ & 16 & 16 \\
E640 & $>16$ & $>16$ & 16 & 16 \\
S23 & $>16$ & 0.25 & $<0.03125$ & $<0.03125$ \\
S49 & $>16$ & 16 & 16 & 16 \\
P304 & $>16$ & 4 & 2 & 2 \\
P386 & $>16$ & 8 & 4 & 4 \\
P582 & $>16$ & $>16$ & $>16$ & $>16$ \\
P671 & $>16$ & 16 & 4 & 4 \\
P723 & $>16$ & 4 & 1 & 1 \\
P727 & $>16$ & 16 & 8 & 8 \\
P729 & $>16$ & 4 & 2 & 2 \\
\hline K K Pneury & & &
\end{tabular}

$\mathrm{K}$, K. pneumoniae; E, E. coli; S, S. aureus; P, P. aeruginosa

that a great amount of antibiotic could be delivered into bacterial cells by Oxi- $\alpha C D$ NPs. In addition, the antibacterial activity of MXF/Oxi- $\alpha$ CD NPs and MXF/FA-Oxi$\alpha C D$ NPs against P727 bacteria was the same because FA modification did not increase the internalization of NPs by bacteria.

As described previously, FA-modified Oxi- $\alpha$ CD NPs can be easily internalized by activated macrophages. To investigate whether our prepared nanomedicines can protect against cellular bacteria, P727 isolate-infected macrophages were employed to evaluate the antibacterial activities of MXF and its nanoformulations. P727 isolateinfected macrophages were treated with MXF, MXF/Oxi$\alpha C D$ NPs or MXF/FA-Oxi- $\alpha$ CD NPs for 4 or $24 \mathrm{~h}$, and the number of surviving bacteria in the infected macrophages was determined. Without any treatment, P727 bacteria showed rapid growth in macrophages (Fig. 5). The number of bacteria in the macrophages decreased with MXF treatment for $4 \mathrm{~h}$, indicating that MXF exerted intracellular antibacterial activity. Compared with the MXF treatment group, the MXF/Oxi- $\alpha C D$ NPs and MXF/FA-Oxi- $\alpha C D$ NPs groups had fewer bacteria in the infected macrophages after $4 \mathrm{~h}$ of treatment, demonstrating that MXF/Oxi- $\alpha C D$ NPs and MXF/FA-Oxi- $\alpha C D$ NPs had better intracellular antibacterial activity than MXF. On the other hand, MXF/FA-Oxi- $\alpha$ CD NPs had slightly better antibacterial activity than MXF/Oxi- $\alpha C D$ NPs due to the increased internalization of FA-modified Oxi$\alpha C D$ NPs by activated macrophages (Fig. 5). After $24 \mathrm{~h}$ of treatment, the number of intracellular bacteria in the control group was decreased due to the eradication of bacteria by macrophages $[2,3]$. Interestingly, the number of bacteria in macrophages was significantly decreased by treatment with MXF-encapsulated NPs compared to MXF, and almost no intracellular bacteria were detected after MXF/FA-Oxi- $\alpha$ CD NPs treatment (Fig. 5). These results indicated that MXF-loaded Oxi- $\alpha C D$ NPs had greater intracellular antibacterial activity than MXF. The reason for this finding is that FA-modified NPs can easily adhere to FR on the surface of macrophages, leading to high internalization of MXF/FA-Oxi- $\alpha C D$ NPs by macrophages and enhanced antibacterial efficacy.

\section{Antibacterial mechanisms of MXF-loaded NPs}

As previously described, MXF/Oxi- $\alpha \mathrm{CD}$ NPs and MXF/ FA-Oxi- $\alpha C D$ NPs had better antibacterial activity and lower MIC values than MXF. To clarify the antibacterial mechanism of MXF-loaded Oxi- $\alpha$ CD NPs, the morphology of bacteria after treatment with nanomedicines or control was observed by TEM. As shown in Fig. 4, cells in the control group had a normal, smooth cellular surface and a larger population. Compared with the control group, the group treated with $1 / 4 \times$ MIC of MXF displayed partial cell surface disruption with slight leakage of cellular cytoplasmic content. Furthermore, bacterial cells treated with MXF/Oxi- $\alpha \mathrm{CD}$ NPs or MXF/ FA-Oxi- $\alpha C D$ NPs showed significant structural changes and complete cellular surface disruption. Meanwhile, the cellular cytoplasmic content of these cells underwent massive outflow, and only the cell membrane fragments remained (Fig. 4, red arrow). Nevertheless, the morphological structure of bacteria treated with MXF/Oxi- $\alpha C D$ NPs or MXF/FA-Oxi- $\alpha C D$ NPs showed no distinct difference. The cell membrane plays a key role in maintaining the normal function of bacteria, including providing a stable physiological environment, enabling the selective transport of substances, shielding water penetration and maintaining biological function. Some bacteria are difficult to kill due to complex cell envelopes with low permeability and extra defense mechanisms [32]. Herein, TEM images revealed that MXF/Oxi- $\alpha C D$ NPs and MXF/ FA-Oxi- $\alpha C D$ NPs could disrupt the cell membrane of $P$. aeruginosa cells to inhibit bacterial growth.

Biofilms are widely associated with persistent bacterial infections with formidable resistance to conventional antiseptic drugs and local immune defense [33]. To further verify the antibacterial mechanism of MXF-loaded NPs, the biofilm formation of bacteria treated with NPs was assayed. As shown in Additional file 1: Figure S8, 


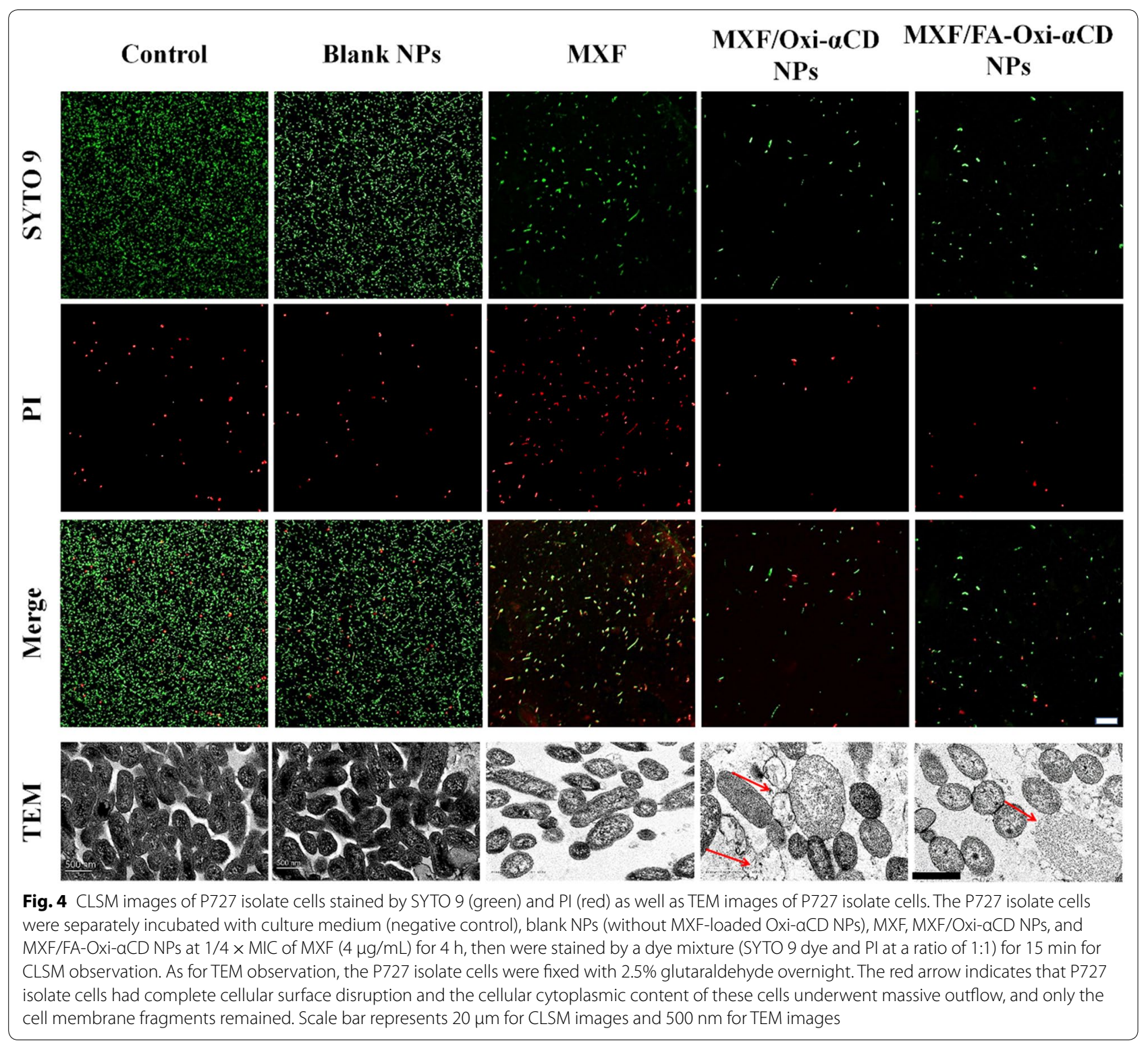

$1 / 4 \times$ MIC of both MXF and nanoformulations suppressed biofilm formation by the P727 isolate. Interestingly, the inhibition of P727 biofilm formation by MXF/ Oxi- $\alpha C D$ NPs and MXF/FA-Oxi- $\alpha C D$ NPs was much stronger than that by MXF and the control. P. aeruginosa can alter its outer membrane permeability to prevent antibiotic entry, resulting in antibiotic resistance [34]. These results indicated that MXF-loaded Oxi- $\alpha C D$ NPs may overcome the drug resistance of bacteria by suppressing bacterial biofilm formation.

As previously mentioned, MXF-loaded Oxi- $\alpha C D$ NPs showed better antibacterial activities than MXF through disrupting the cell membrane and suppressing bacterial biofilm formation. However, the underlying mechanism is still unclear. MXF is a DNA topoisomerase inhibitor, which exerts antibacterial activities by damaging cellular DNA. Therefore, we speculated that MXF-loaded Oxi$\alpha C D$ NPs could effectively bind to bacteria and deliver more MXF molecules into cells. To test this hypothesis, the interaction of NPs and bacteria was directly observed by CLSM (Additional file 1: Figure S9). Compared with free Cy5, Cy5-labeled Oxi- $\alpha$ CD NPs and MXF/FA-Oxi$\alpha C D$ NPs efficiently bound to bacteria. It has been reported that NPs can bind to bacteria through electrostatic, hydrophobic and van der Waals interactions [31]. Paunov et al. discovered that the antibacterial activity of copper oxide NPs was notably enhanced by boronic acid surface functionality because boronic acid can bind to the 


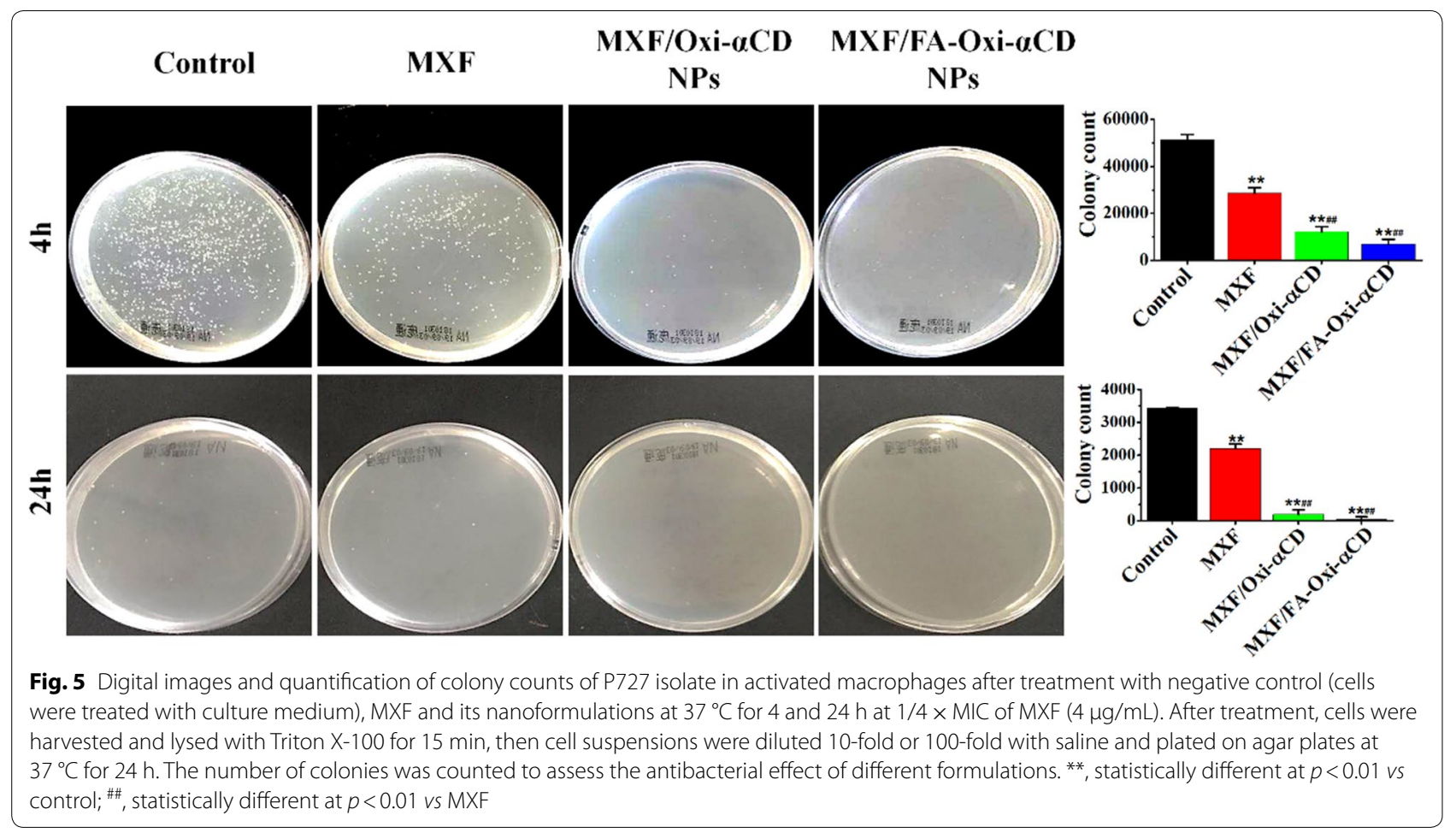

saccharide on the surface of bacterial cells [35]. Herein, the strong binding ability of ROS-responsive NPs to bacteria increased the uptake of NPs by bacteria, leading to more antibiotics entering bacterial cells and enhanced antibacterial activity.

\section{Evaluation of in vivo biodistribution}

Pulmonary $P$. aeruginosa infection is usually accompanied by an inflammatory response, with abundant active macrophages accumulated at infection sites [2, 3, 36]. To investigate the targeting capability of NPs to the lung tissues, the biodistribution of Cy5-labeled NPs was analyzed in a mouse model of pulmonary infection using in vivo imaging assays. Ex vivo fluorescence images of excised tissues confirmed that mice injected with free Cy5 had weak fluorescence at different time points, suggesting that the free drug had low biodistribution in the lung tissues (Fig. 6a). Compared to the Cy5 group, the Cy5-labeled Oxi- $\alpha C D$ NPs group showed enhanced fluorescence in the lung tissues at $2 \mathrm{~h}$ post injection, and the fluorescence signals reached a maximum at $12 \mathrm{~h}$ post injection. After $24 \mathrm{~h}$ post injection, bright fluorescence signals were still observed in the lung tissues after treatment with Cy5-labeled Oxi- $\alpha C D$ NPs, indicating that NPs have longer retention times than the free drug. It is worth noting that mice injected with Cy5/FA-Oxi- $\alpha \mathrm{CD}$ NPs displayed the strongest fluorescence intensity in the lung tissues at 4, 6, 8, 12 and $24 \mathrm{~h}$ post injection (Fig. 6a).
These results proved that the targeting capability of $\mathrm{Cy} 5 /$ FA-Oxi- $\alpha C D$ NPs to infected lung tissues was increased by modification with FA, indicating that FA-modified Oxi- $\alpha C D$ NPs could serve as an effective platform to site-specifically deliver therapeutics to the infected lung tissues. However, strong fluorescence signals in the liver and spleen tissues were observed at different time points. Mikhail O Durymanov et al. summarized that NPs with diameters $>200 \mathrm{~nm}$ can be trapped by lung, spleen, and liver macrophages [37]. Enhanced uptake in the liver and spleen is attributed to macrophages, which play a crucial role in eliminating macromolecules and NPs circulating in the blood [38]. These factors resulted in high accumulation of Oxi- $\alpha C D$ NPs in liver and spleen tissues.

In some lung diseases, such as cystic fibrosis, lung function is compromised by the formation of purulent viscous mucus secretions, which benefit bacterial accumulation and survival [39]. The viscosity of mucus is increased because infected bacteria can stimulate the release of neutrophil chemoattractants from neutrophils and epithelial cells [40]. It is difficult for free drugs to penetrate the viscous mucus, leading to inadequate exposure of resident bacteria to antibiotics [41]. PEGylated NPs can efficiently penetrate the mucus due to the hydrophilic properties of PEG that can prevent the interaction between NPs and mucus (including DNA and other components), thereby improving the diffusion of NPs [42]. Therefore, the PEGylation strategy is widely used 


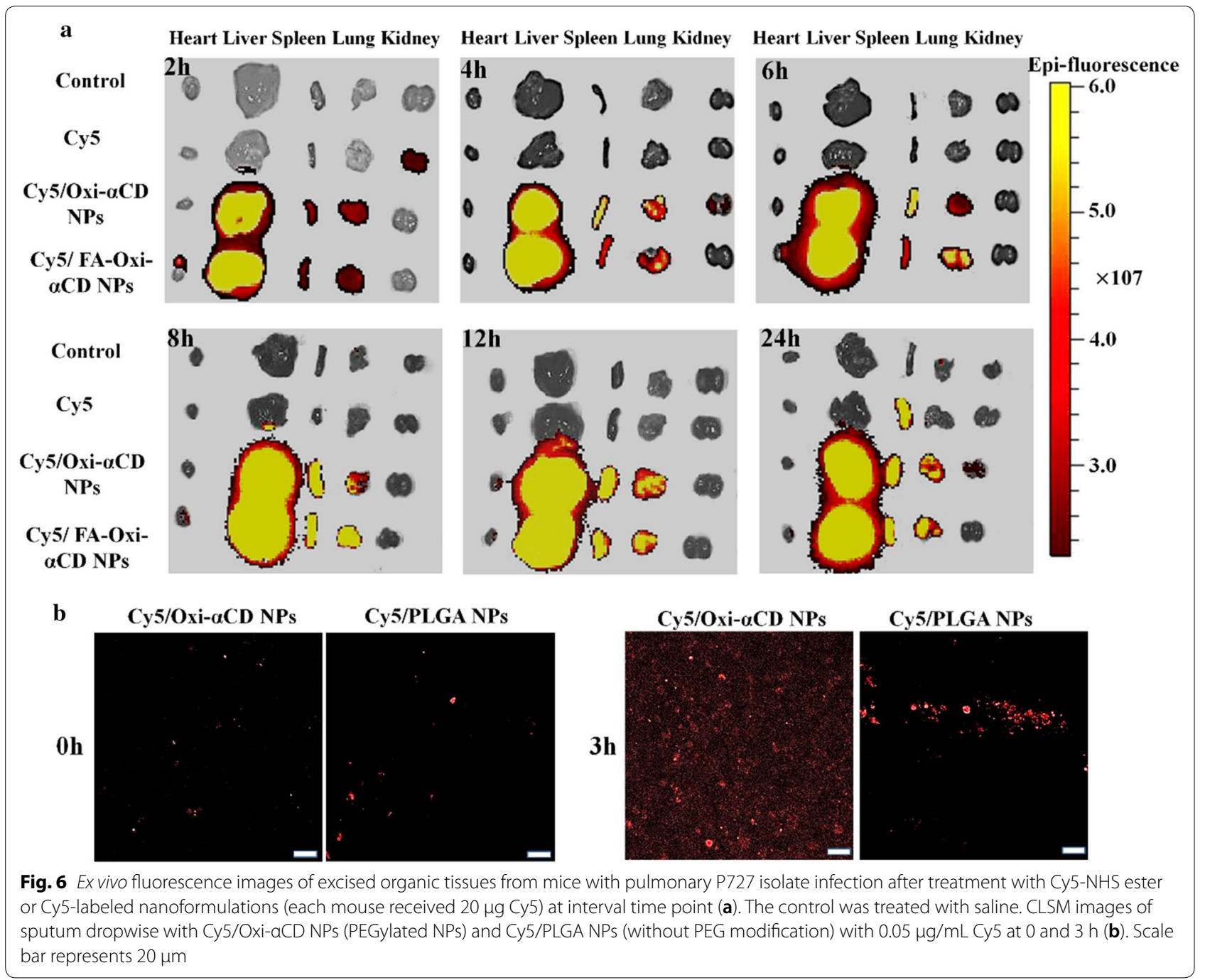

to treat mucus-heavy diseases such as pulmonary disease [39, 43], ocular disease [44], and vaginal disease [45]. DSPE-PEG-modified liposomes were also employed to treat mucus resident bacteria, such as Helicobacter pylori [46]. To penetrate mucus in the pulmonary tissues, we employed DSPE-PEG, a biocompatible material that has been extensively used as a drug/gene carrier to decorate NPs. The penetration ability of Cy5-labeled Oxi- $\alpha C D$ NPs in sputum was tested in vitro by CLSM via a layer-bylayer scanning model. At the beginning of the test, both Cy5/Oxi- $\alpha C D$ NPs and Cy5/PLGA NPs (no PEG coating) were assembled on the surface of sputum (Fig. 6b). After $3 \mathrm{~h}$ of incubation, Cy5/Oxi- $\alpha \mathrm{CD}$ NPs penetrated through the sputum and dispersed in all directions. However, Cy5/PLGA NPs showed poor penetration and dispersion in the sputum (Fig. 6b). From these results, we demonstrated that PEGylated Oxi- $\alpha C D$ NPs could efficiently penetrate mucus and serve as a nanovehicles to deliver therapeutics to mucus-coated pulmonary tissues.

\section{In vivo anti-infective activity}

These encouraging in vitro results on the antibacterial efficacy of MXF-encapsulated Oxi- $\alpha C D$ NPs prompted us to explore whether these nanomedicines are effective therapeutics for the treatment of pulmonary $P$. aeruginosa infection in vivo. To investigate whether MXF-loaded Oxi- $\alpha C D$ NPs could prolong the survival time of pulmonary $P$. aeruginosa-infected mice, a high concentration of bacteria $\left(1 \times 10^{8} \mathrm{CFU} / \mathrm{mL}\right)$ was injected into the lung tissues of immunosuppressed mice. The survival curve showed that infected mice treated with saline died within $48 \mathrm{~h}$ (Fig. 7a). Administration of MXF could prolong the survival time of mice to 6 days $(20 \%$ survival rate), indicating that MXF has in vivo antibacterial efficacy. The survival rate of the mice treated with MXF/ Oxi- $\alpha$ CD NPs or MXF alone was the same, while a $40 \%$ survival rate was obtained after treatment with MXF/ FA-Oxi- $\alpha C D$ NPs. In vivo anti-infective experiments 
suggested that MXF/FA-Oxi- $\alpha$ CD NPs could increase the antibacterial activity of MXF.

After the experiment, all examined mice were sacrificed, and lung tissues were harvested to further investigate in vivo antibacterial efficacy of the MXF-loaded nanoformulations. The left lung tissues were collected for $H \& E$ staining and pathology analysis. Examination on H\&E-stained sections of lung tissues revealed no significant pathological abnormalities or injuries in normal mice. However, a destroyed, incomplete alveolar wall structure, and many black bacteria colonies were observed in the lungs of mice infected with bacteria and treated with saline or blank NPs (Fig. 7b, red arrow). Compared with the saline or blank NPs group, the MXF, MXF/Oxi- $\alpha C D$ NPs and MXF/FA-Oxi- $\alpha C D$ NPs groups had relatively complete lung tissues structure and fewer bacterial colonies. In particular, almost no bacterial colonies could be found in the lungs after MXF/FA-Oxi$\alpha C D$ NPs treatment (Fig. 7b). The right lung tissues were removed to quantitatively determine the bacteria count per weight $(\mathrm{CFU} / \mathrm{g})$. The colony count images showed fewer pulmonary bacteria in MXF-treated mice than those treated with saline or blank NPs. Moreover, mice treated with MXF/Oxi- $\alpha \mathrm{CD}$ NPs had fewer pulmonary bacteria than MXF-treated mice. Remarkably, almost no bacteria were detected in the lungs of infected mice treated with MXF/FA-Oxi- $\alpha$ CD NPs (Fig. 7c, d). These results are consistent with the previous $\mathrm{H} \& \mathrm{E}$ results. Although MXF/FA-Oxi- $\alpha$ CD NPs could efficiently eliminate infected bacteria from the lung tissues, the survival time of these mice was only slightly prolonged compared to those in the free drug group. The reason may be that all the experimental mice were immunosuppressed and
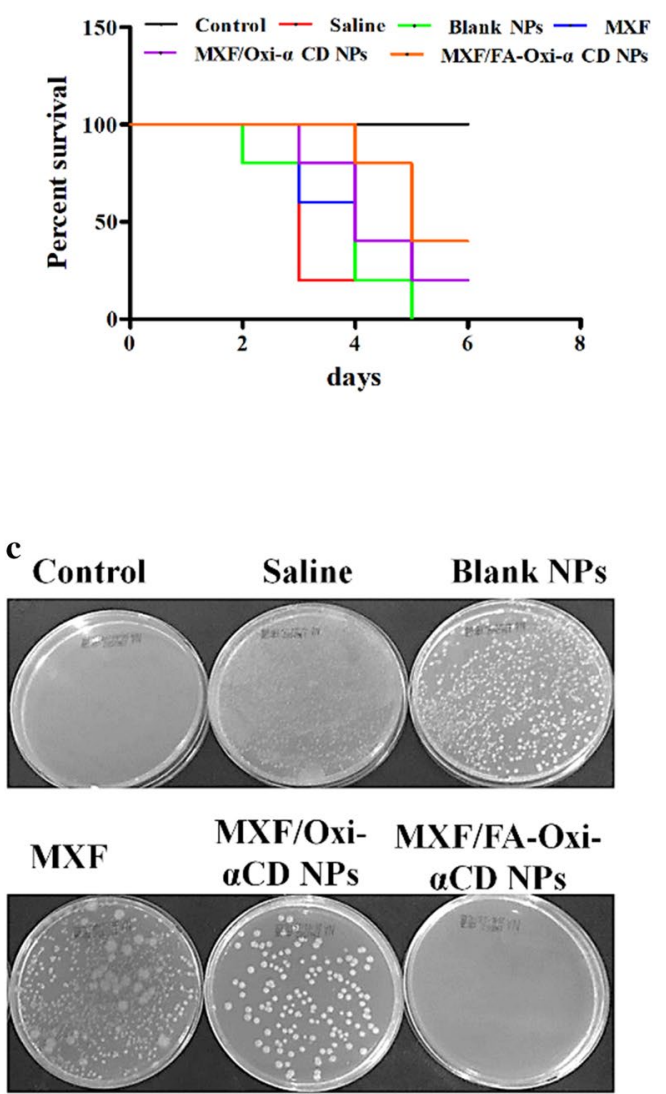

b

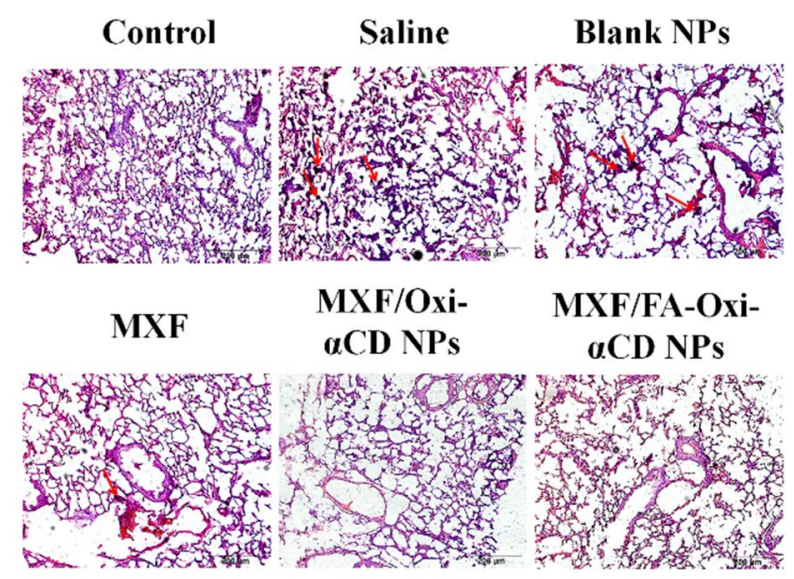

d

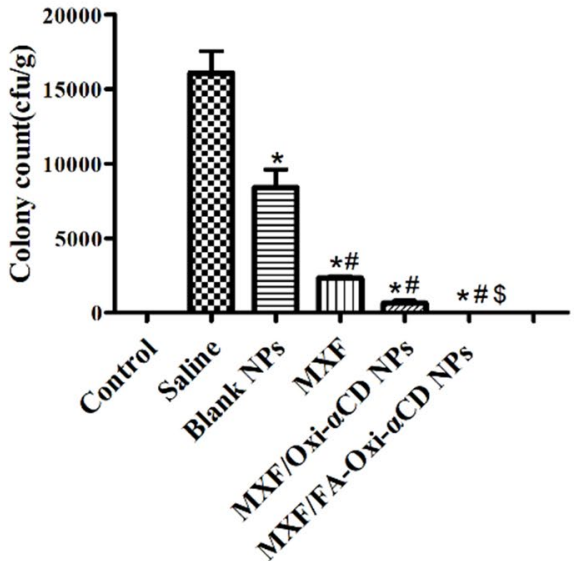

Fig. 7 In vivo antibacterial efficacy of MXF and its nanoformulations in mice with pulmonary P727 isolate infection. Survival rate of bacteria-infected mice treated with saline, blank NPs (without MXF-loaded Oxi-aCD NPs), MXF, and MXF nanoformulations (each group included five mice, each mouse received two dose of free drug or MXF-loaded NPs with $5 \mathrm{mg} / \mathrm{kg}$ of MXF at interval 2 days, while mice in the blank NPs group received equal NPs with the drug-loaded NPs group) (a). H\&E-stained sections of the lung tissues from normal and infected mice (b). The images and colony counts of P727 isolate of lung tissues $(\mathbf{c}, \mathbf{d})$. The red arrow indicates that P727 isolate colony was observed in the infected lung tissues. ${ }^{*}$ statistical

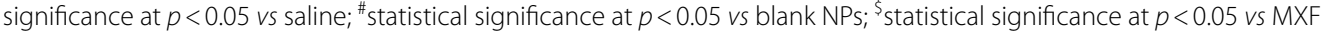


had a serious pulmonary bacterial infection and were too weak to survive for a long time.

All the results demonstrated that FA-modified ROSresponsive NPs can efficiently deliver MXF to infected lung tissues and enhance its antibacterial efficacy in a murine model of pulmonary $P$. aeruginosa infection. Therefore, MXF/FA-Oxi- $\alpha$ CD NPs can be further developed as a safe and efficacious nanomedicine for the targeted treatment of pulmonary diseases.

\section{Conclusion}

Pulmonary bacterial infections seriously threaten the health of patients, especially immunocompromised patients and those with lung dysfunction. Targeted delivery of therapeutics to pulmonary tissues is a promising strategy to treat pulmonary bacterial infections. Herein, we developed a ROS-responsive nanoplatform to encapsulate MXF for the targeted treatment of pulmonary $P$. aeruginosa infection. MXF-loaded Oxi- $\alpha C D$ NPs can efficiently penetrate sputum due to the peripheral PEG coating. Furthermore, MXF can be rapidly released from NPs in the presence of $\mathrm{H}_{2} \mathrm{O}_{2}$. In vitro antibacterial assay demonstrated that MXF-loaded Oxi- $\alpha C D$ NPs have greater antibacterial efficacy than MXF against $P$. aeruginosa. In vivo biodistribution images showed that FAmodified Oxi- $\alpha C D$ NPs can be notably accumulated in infected lung tissues due to FA receptor overexpression on the surface of activated macrophages recruited to sites of inflammation. In a mouse model of pulmonary infection, MXF/FA-Oxi- $\alpha$ CD NPs can more efficiently eliminate bacteria from the lung tissues compared to MXF and MXF/Oxi- $\alpha C D$ NPs. The survival time of the mice was prolonged by treatment with MXF/Oxi- $\alpha$ CD NPs. Of note, the active targeting capability, mucus penetration ability, and controlled drug release of MXF/FA-Oxi- $\alpha C D$ NPs increased the drug concentration in pathological tissues and enhanced the antibacterial activity in vivo. In summary, FA-modified Oxi- $\alpha$ CD NPs can serve as an effective and safe drug delivery platform for the targeted treatment of pulmonary bacterial infection.

\section{Supplementary information}

Supplementary information accompanies this paper at https://doi. org/10.1186/s12951-019-0537-4.

Additional file 1. Additional materials include the synthesis scheme of the materials and their ${ }^{1} \mathrm{HNMR}$ spectra, intracellular and extracellular $\mathrm{H}_{2} \mathrm{O}_{2}$ concentration detection, cytotoxicity of the nanoformulations, CLSM images of the cell uptake of NPS, cell uptake efficiency determined by flow cytometry, biofilm formation, and CLSM images of bacteria interacted with NPs.

\section{Acknowledgements}

The authors are grateful for financial support from the Southwest Hospital Foundation (Grant No. SWH2017jCZD-04).

\section{Authors' contributions}

YW performed the major experiments, and drafted the manuscript. QY, WF, $\mathrm{XL}$, and $\mathrm{BY}$ participated in the animal experiments. QD, LC, JW assessed the in vitro antibacterial activity. JD and $\mathrm{HZ}$ analyzed the experimental data. WP constructed the figures. FS and DZ designed the study and drafted the manuscript. All authors read and approved the final manuscript.

Ethics approval and consent to participate Not applicable.

\section{Consent for publication}

Not applicable.

\section{Competing interests}

The authors declare that they have no competing interests.

\section{Author details \\ ${ }^{1}$ Department of Pharmacy, Southwest Hospital, Army Medical University (Third Military Medical University), Chongqing 400038, China. ${ }^{2}$ Department of Chemistry, College of Basic Medicine, Army Medical University (Third Military Medical University), Chongqing 400038, China. ${ }^{3}$ Department of Ultra- sound, Southwest Hospital, Army Medical University (Third Military Medical University), Chongqing 400038, China. ${ }^{4}$ Department of Scientific Research Affairs, Army Medical University (Third Military Medical University), Chong- qing 400038, China. ${ }^{5}$ Department of Pharmacy, Handan Branch of Chinese PLA 980 Hospital, Handan 056000, Hebei, China. ${ }^{6}$ Department of Neurosur- gery, Southwest Hospital, Army Medical University (Third Military Medical University), Chongqing 400038, China.}

Received: 10 July 2019 Accepted: 24 September 2019

Published online: 03 October 2019

\section{References}

1. Lyczak JB, Cannon CL, Pier GB. Lung infections associated with cystic fibrosis. Clin Microbiol Rev. 2002;15(2):194-222.

2. Guilliams M, Lambrecht BN, Hammad H. Division of labor between lung dendritic cells and macrophages in the defense against pulmonary infections. Mucosal Immunol. 2013;6(3):464-73.

3. Goldstein E, Lippert W, Warshauer D. Pulmonary alveolar macrophage. Defender against bacterial infection of the lung. J Clin Invest. 1974;54(3):519-28.

4. LeVine AM, Whitsett JA, Gwozdz JA, Richardson TR, Fisher JH, Burhans MS, Korfhagen TR. Distinct effects of surfactant protein A or D deficiency during bacterial infection on the lung. J Immunol. 2000;165(7):3934-40.

5. Loeuillet C, Martinon F, Perez C, Munoz M, Thome M, Meylan PR. Mycobacterium tuberculosis subverts innate immunity to evade specific effectors. J Immunol. 2006;177(9):6245-55.

6. Blondeau JM, Hansen GT. Moxifloxacin: a review of the microbiological, pharmacological, clinical and safety features. Expert Opin Pharmacother. 2001;2(2):317-35.

7. Soto S, Lopez-Roses L, Avila S, Lancho A, Gonzalez A, Santos E, Urraca B. Moxifloxacin-induced acute liver injury. Am J Gastroenterol. 2002;97(7):1853-4.

8. Mustafa S, Devi VK, Pai RS. Effect of PEG and water-soluble chitosan coating on moxifloxacin-loaded PLGA long-circulating nanoparticles. Drug Deliv Transl Res. 2017;7(1):27-36.

9. Puligujja P, McMillan J, Kendrick L, Li T, Balkundi S, Smith N, Veerubhotla RS, Edagwa BJ, Kabanov AV, Bronich T, et al. Macrophage folate receptortargeted antiretroviral therapy facilitates drug entry, retention, antiretroviral activities and biodistribution for reduction of human immunodeficiency virus infections. Nanomedicine. 2013;9(8):1263-73.

10. Chono S, Tanino T, Seki T, Morimoto K. Efficient drug targeting to rat alveolar macrophages by pulmonary administration of ciprofloxacin incorporated into mannosylated liposomes for treatment of respiratory intracellular parasitic infections. J Control Release. 2008;127(1):50-8. 
11. Fernandez M, Javaid F, Chudasama V. Advances in targeting the folate receptor in the treatment/imaging of cancers. Chem Sci. 2018;9(4):790-810.

12. Elnakat $H$, Ratnam M. Distribution, functionality and gene regulation of folate receptor isoforms: implications in targeted therapy. Adv Drug Deliv Rev. 2004;56(8):1067-84.

13. Xia W, Hilgenbrink AR, Matteson EL, Lockwood MB, Cheng JX, Low PS. A functional folate receptor is induced during macrophage activation and can be used to target drugs to activated macrophages. Blood. 2009;113(2):438-46.

14. Yi YS. Folate receptor-targeted diagnostics and therapeutics for inflammatory diseases. Immune Netw. 2016;16(6):337-43.

15. Luciani A, Villella VR, Esposito S, Brunetti-Pierri N, Medina D, Settembre C, Gavina M, Pulze L, Giardino I, Pettoello-Mantovani M, et al. Defective CFTR induces aggresome formation and lung inflammation in cystic fibrosis through ROS-mediated autophagy inhibition. Nat Cell Biol. 2010;12(9):863-75.

16. Winterbourn CC. Reconciling the chemistry and biology of reactive oxygen species. Nat Chem Biol. 2008;4(5):278-86.

17. Dharmaraja AT. Role of reactive oxygen species (ROS) in therapeutics and drug resistance in cancer and bacteria. J Med Chem. 2017;60(8):3221-40.

18. Van Acker $\mathrm{H}$, Coenye T. The role of reactive oxygen species in antibioticmediated killing of bacteria. Trends Microbiol. 2017;25(6):456-66.

19. Imlay JA. Transcription factors that defend bacteria against reactive oxygen species. Annu Rev Microbiol. 2015;69:93-108.

20. Li H, Horke S, Forstermann U. Oxidative stress in vascular disease and its pharmacological prevention. Trends Pharmacol Sci. 2013;34(6):313-9.

21. Joshi-Barr S, de Gracia Lux C, Mahmoud E, Almutairi A. Exploiting oxidative microenvironments in the body as triggers for drug delivery systems. Antioxid Redox Signal. 2014;21(5):730-54.

22. El-Mohtadi F, d'Arcy R, Tirelli N. Oxidation-responsive materials: biological rationale, state of the art, multiple responsiveness, and open issues. Macromol Rapid Commun. 2019;40(1):e1800699.

23. Lux CD, Joshi-Barr S, Nguyen T, Mahmoud E, Schopf E, Fomina N, Almutairi A. Biocompatible polymeric nanoparticles degrade and release cargo in response to biologically relevant levels of hydrogen peroxide. J Am Chem Soc. 2012;134(38):15758-64.

24. Zhang DL, Wei YL, Chen K, Zhang XJ, Xu XQ, Shi Q, Han SL, Chen X, Gong $H$, Li XH, et al. Biocompatible reactive oxygen species (ROS)-responsive nanoparticles as superior drug delivery vehicles. Adv Healthc Mater. 2015;4(1):69-76

25. Zhang QX, Zhang FZ, Chen Y, Dou Y, Tao H, Zhang DL, Wang RB, Li XH, Zhang JX. Structure-property correlations of reactive oxygen speciesresponsive and hydrogen peroxide-eliminating materials with anti-oxidant and anti-inflammatory activities. Chem Mater. 2017;29(19):8221-38.

26. Dou Y, Chen Y, Zhang XJ, Xu XQ, Chen YD, Guo JW, Zhang DL, Wang RB, Li $\mathrm{XH}$, Zhang JX. Non-proinflammatory and responsive nanoplatforms for targeted treatment of atherosclerosis. Biomaterials. 2017;143:93-108.

27. Shi HQ, Sun FJ, Chen JH, Yong XL, Ou QY, Feng W, Xia PY. Opposite effects of cefoperazone and ceftazidime on Sribosylhomocysteine lyase/autoinducer-2 quorum sensing and biofilm formation by an Escherichia coli clinical isolate. Mol Med Rep. 2014;10(5):2334-40.

28. Zhang QX, Tao H, Lin YY, Hu Y, An HJ, Zhang DL, Feng SB, Hu HY, Wang $\mathrm{RB}$, Li XH, et al. A superoxide dismutase/catalase mimetic nanomedicine for targeted therapy of inflammatory bowel disease. Biomaterials. 2016;105:206-21.

29. Prasad G, Dhar V, Mukhopadhaya A. Vibrio cholerae OmpU mediates CD36-dependent reactive oxygen species generation triggering an additional pathway of MAPK activation in macrophages. J Immunol. 2019;202(8):2431-50

30. Harms A, Maisonneuve E, Gerdes K. Mechanisms of bacterial persistence during stress and antibiotic exposure. Science. 2016;354(6318):aaf4268. https://doi.org/10.1126/science.aaf4268
31. Hong W, Zhao YN, Guo YR, Huang CC, Qiu P, Zhu J, Chu C, Shi H, Liu MC. PEGylated self-assembled nano-bacitracin A: probing the antibacterial mechanism and real-time tracing of target delivery in vivo. Acs Appl Mater Inter. 2018;10(13):10688-705.

32. Xiao F, Cao B, Wang C, Guo X, Li M, Xing D, Hu X. Pathogen-specific polymeric antimicrobials with significant membrane disruption and enhanced photodynamic damage to inhibit highly opportunistic bacteria. ACS Nano. 2019;13(2):1511-25.

33. Mahmoud MY, Demuth DR, Steinbach-Rankins JM. BAR-encapsulated nanoparticles for the inhibition and disruption of Porphyromonas gingivalis-Streptococcus gordonii biofilms. J Nanobiotechnology. 2018;16(1):69.

34. Flemming HC, Wingender J, Szewzyk U, Steinberg P, Rice SA, Kjelleberg S. Biofilms: an emergent form of bacterial life. Nat Rev Microbiol. 2016;14(9):563-75.

35. Halbus AF, Horozov TS, Paunov VN. Strongly enhanced antibacterial action of copper oxide nanoparticles with boronic acid surface functionality. Acs Appl Mater Inter. 2019;11(13):12232-43.

36. Leopold Wager CM, Wormley FL Jr. Classical versus alternative macrophage activation: the Ying and the Yang in host defense against pulmonary fungal infections. Mucosal Immunol. 2014;7(5):1023-35.

37. Durymanov MO, Rosenkranz AA, Sobolev AS. Current approaches for improving intratumoral accumulation and distribution of nanomedicines. Theranostics. 2015;5(9):1007-20.

38. Li SD, Huang L. Pharmacokinetics and biodistribution of nanoparticles. Mol Pharm. 2008;5(4):496-504.

39. Deacon J, Abdelghany SM, Quinn DJ, Schmid D, Megaw J, Donnelly RF, Jones DS, Kissenpfennig A, Elborn JS, Gilmore BF, et al. Antimicrobial efficacy of tobramycin polymeric nanoparticles for Pseudomonas aeruginosa infections in cystic fibrosis: formulation, characterisation and functionalisation with dornase alfa (DNase). J Control Release. 2015;198:55-61.

40. Fahy JV, Dickey BF. Airway mucus function and dysfunction. N Engl J Med. 2010;363(23):2233-47.

41. Hunt BE, Weber A, Berger A, Ramsey B, Smith AL. Macromolecular mechanisms of sputum inhibition of tobramycin activity. Antimicrob Agents Chemother. 1995:39(1):34-9.

42. Bahamondez-Canas TF, Zhang H, Tewes F, Leal J, Smyth HDC. PEGylation of tobramycin improves mucus penetration and antimicrobial activity against Pseudomonas aeruginosa biofilms in vitro. Mol Pharm. 2018;15(4):1643-52.

43. Schneider CS, Xu Q, Boylan NJ, Chisholm J, Tang BC, Schuster BS, Henning A, Ensign LM, Lee E, Adstamongkonkul P, et al. Nanoparticles that do not adhere to mucus provide uniform and long-lasting drug delivery to airways following inhalation. Sci Adv. 2017;3(4):e1601556.

44. Schopf LR, Popov AM, Enlow EM, Bourassa JL, Ong WZ, Nowak P, Chen H. Topical ocular drug delivery to the back of the eye by mucus-penetrating particles. TransI Vis Sci Technol. 2015;4(3):11.

45. Lechanteur A, Furst T, Evrard B, Delvenne P, Piel G, Hubert P. Promoting vaginal distribution of E7 and MCL-1 siRNA-silencing nanoparticles for cervical cancer treatment. Mol Pharm. 2017;14(5):1706-17.

46. Santos RS, Dakwar GR, Zagato E, Brans T, Figueiredo C, Raemdonck K, Azevedo NF, De Smedt SC, Braeckmans K. Intracellular delivery of oligonucleotides in Helicobacter pylori by fusogenic liposomes in the presence of gastric mucus. Biomaterials. 2017;138:1-12.

\section{Publisher's Note}

Springer Nature remains neutral with regard to jurisdictional claims in published maps and institutional affiliations. 